\title{
EDUCAÇÃO DE MENINAS ÓRFÃS NA CONCEPÇÃO DO INTENDENTE ANTÔNIO LEMOS EM BELÉM DO PARÁ (1900 - 1906)
}

\author{
Adriene Suellen Ferreira Pimenta ${ }^{1}$ \\ Maria do Perpétuo Socorro Gomes Avelino de França² \\ Universidade do Estado do Pará
}

\section{RESUMO}

O "Orfanato Municipal Antônio Lemos" teve suas origens na Associação Protectora dos Orphãos, em 1893, com o propósito de abrigar e educar meninas órfãs. Alguns anos mais tarde, o Intendente da época, Antônio José de Lemos, publicou uma lei que lhe dava autonomia para reorganizar o Orfanato e dar forma ao ensino das órfãs. Ora, na concepção de Antônio Lemos, como deveria se dar a educação dessas meninas órfãs? O objetivo deste estudo é analisar a concepção de Lemos em relação à educação dessas meninas. Para isso, utilizamos como fontes os Relatórios da Intendência Municipal de Belém, entre os anos de 1900 e 1906. O estudo conclui que o Intendente Antônio Lemos concebia, para as órfãs, uma educação voltada para o lar, para serem boas mães e esposas exemplares, mas não era qualquer educação, visto que as órfãs tinham que aprender as primeiras letras, literatura e canto.

Palavras-chave: Instituição Educativa. Orfanato. Educação de Meninas.

\section{EDUCATION OF ORPHAN GIRLS IN THE CONCEPTION OF INTENDANT ANTÔNIO LEMOS IN BELÉM, PARÁ (1900-1906)}

\begin{abstract}
The "Orfanato Municipal Antônio Lemos" [Municipal Orphanage Antônio Lemos] had its origins in Associação Protectora dos Orphãos [Association for the Protection of Orphans], in 1893. It had the purpose of sheltering and educating orphan girls. A few years later, the Intendant at the time, Antônio José de Lemos, issued a law that gave him autonomy to reorganize the Orphanage and give shape to the teaching of the orphans. Well, in the conception of Antônio Lemos, how should the education of these orphan girls be carried out? The objective of this study is to analyze Lemos' conception regarding the education of these girls. For that, we use as sources the Reports of the Municipal Intendancy of Belém, between the years 1900 and 1906. The study concluded that Intendant Antônio Lemos conceived for the orphans an education targeted at the home, for them to be good mothers and exemplary wives, but this was no ordinary education, considering that the orphans had to learn the first letters, literature, singing.
\end{abstract}

Keywords: Educational Institution. Orphanage. Education of Girls.

\section{INTRODUÇÃO}

Este artigo analisa a concepção de educação de meninas órfãs, do Intendente Antônio Lemos, no "Orfanato Antônio Lemos", no período de 1900 a 1906. Tal instituição teve suas origens na "Associação Protectora dos Órfãos", em 1893, em Belém/PA, sendo 
denominada inicialmente de "Orphelinato Paraense". Esse Orfanato tinha como objetivo amparar e educar meninas órfãs, mantidas por associados e por doações. No entanto, no ano de 1900, os recursos arrecadados passaram a ser insuficientes para manter a instituição. Nesse período, a diretoria do Orfanato pediu ajuda à Intendência Municipal de Belém, a qual tinha como principal representante na época, o Intendente Antônio Lemos. Mas, quem foi Antônio Lemos?

Conforme Rocque (1977), Antônio José de Lemos nasceu em São Luís, no Maranhão, dia 17 de dezembro de 1843. Filho de Olivia de Souza Lemos e do capitão-mor da antiga milícia Antônio José de Lemos. Teve uma infância e adolescência humilde. Realizou o cursou secundário no "Liceu do Maranhão". Com dezessete anos de idade, inscreveu-se na Marinha de Guerra. Seguiu carreira militar e, no dia 2 de fevereiro 1867, aos vinte e quatro anos, Lemos pisou pela primeira vez em solo paraense na condição de secretário particular do Almirante e, em seguida, oficial da quarta classe do Corpo da Fazenda.

De acordo com Sarges (2002), Lemos firmou-se definitivamente em Belém no momento em que foi convidado a assumir o cargo de Secretário do Arsenal de Marinha, pelo capitão-de-mar-e-guerra Manuel Carneiro da Rocha. Concomitante a esse cargo, assumiu, também, o de secretário da Capitania do Porto do Pará.

Toda a vida e trajetória política de Lemos têm sido narradas por Maria de Nazaré Sarges (2002), na obra Memórias do Velho Intendente. De acordo com essa estudiosa, Lemos estreou como jornalista na redação de "O Pelicano", o qual veio a falir. A tipografia desse jornal foi comprada por Francisco de Sousa Cerqueira, que, mais tarde, se juntou a Joaquim José de Assis, chefe do Partido Liberal ${ }^{3}$ e a Antônio Lemos, dando origem, em 1876, ao jornal diário "A Província do Pará".

Para Manoel (1996), a implantação do projeto Liberal no Brasil significou a organização da oligarquia para uma nova ordenação política sem ideias revolucionárias, sem exclusões, mas sim com agregações e redistribuições. Assim, ao mesmo tempo em que ocorria essa nova ordenação política, Lemos assumia a redação do jornal "A Província do Pará", ao lado de Dr. Assis, o fundador. Destacou-se como jornalista ao conseguir dinamizar o jornal, chegando a ensinar aos gazeteiros sobre as notícias que deveriam ser selecionadas e veiculadas nos jornais da época.

A carreira política de Antônio Lemos se iniciou em 1885, quando o Partido Liberal, do qual era membro, o elegeu Deputado Provincial pelo $1^{\circ}$ e $5^{\circ}$ Distrito. Quando ocorreu a Proclamação da República, Lemos estava exercendo cargo de Presidente da Câmara Municipal, pois havia sido eleito Vereador em 1889. Dessa forma, foi Lemos que empossou a primeira junta constituída por Justo Chermont, José Maria do Nascimento e José Fernando Júnior, que passaram a governar o Pará nos primeiros momentos do regime republicano.

Ao ser instalada a República, os partido monarquistas foram extintos. Assim, foi fundado o Partido Republicano, com ideias tanto dos Liberais quanto dos Conservadores ${ }^{4}$. Posteriormente, por medo do socialismo, os grupos uniram-se aos Republicanos Históricos, fundando, em 1896, o Partido Republicano Paraense. Sarges (2002, p. 48), baseada na ata do Conselho Municipal de 1896, informa que "persistia a mesma estrutura econômica, pois o poder continuava nas mãos das velhas oligarquias", de forma que o Pará continuava sendo comandado por Justo Chermont.

Antônio Lemos tinha como correligionários o médico José Paes de Carvalho e os irmãos Pedro e Justo Chermont. Assumiu a presidência do Partido Republicano no momento em que Paes de Carvalho, o então presidente, precisou ausentar-se do Pará. No entendimento de Sarges (2002), Lemos foi ganhando prestígio e um dos fatores que 
contribuíram para isso foi a atenção que dispensava aos Intendentes do interior, o que também era reportado em seu jornal.

Em 1897, Paes de Carvalho foi eleito Governador do estado do Pará, substituindo Lauro Sodré. Nesse momento, Sodré e Justo Chermont deixaram o Partido Republicano e passaram a ser seus opositores políticos. Nesse mesmo ano, no dia 22 de julho, Lemos foi eleito, pela primeira vez, Intendente de Belém. Lauro Sodré, que já havia rompido com o Partido Liberal, passou a ser o principal opositor político do novo intendente (SARGES, 2002).

Começou a surgir em Belém um embate político, que passou a dividir a opinião da própria população. De um lado, estavam os que simpatizavam com Lemos, popularmente chamados de "Lemistas", e de outro, os que eram a favor das causas de Lauro Sodré, denominados "Lauristas". Contudo, a força política de Lemos o levou a ser eleito duas vezes Senador do Estado e, por cinco vezes, Intendente de Belém, permanecendo por quatorze anos no poder.

O Intendente era eleito por três anos e tinha como função presidir as seções do Conselho Municipal ${ }^{5}$, além de ser o executor de todas as suas resoluções, sendo ainda o chefe do executivo municipal ${ }^{6}$. (O PARÁ, 1908). Assim, por muitos anos, Lemos foi a autoridade política do município, sendo, portanto, quem regia as ações governamentais municipais, administrando os recursos para o "embelezamento da cidade". Dentre as ações realizadas em prol do embelezamento da cidade, estava o abrigo e amparo dos órfãos desvalidos, o que levou as políticas instituídas por Lemos a ter ligação direta com o Orfanato e as transformações lá ocorridas, principalmente no momento em que tal instituição passou a ser responsabilidade do município.

Nos anos de 1902 a 1906, podemos perceber de forma mais direta as ações de Lemos em relação ao Orfanato, visto que no ano de 1900, quando o "Orphelinato Paraense" passou por problemas financeiros, a diretoria da instituição recorreu à Intendência de Belém em busca de auxílio. A partir de então, a Intendência de Belém passou a ajudar o Orphelinato com recursos financeiros e, no ano de 1902, resolveu transferi-lo para o âmbito municipal. Foi então que o intendente Antônio Lemos criou uma Lei municipal que lhe dava autonomia para reorganizar e modelar o ensino das órfãs.

Após traçarmos essas linhas sobre a história desse Orfanato e sua estreita relação com o Intendente Antônio Lemos, ocorreu-nos o seguinte questionamento: Na concepção de Antônio Lemos, como deveria se dar a educação dessas meninas órfãs?

Com o intuito de responder a esse questionamento, elegemos os Relatórios da Intendência Municipal de Belém dos anos de 1900 a 1906. Os relatórios estão dispostos no formato de papel A4, contendo cada um em torno de quatrocentas e setenta páginas, de textos e ilustrações. Esses documentos tratam de assuntos relacionados à administração municipal, como finanças, iluminação, saúde, saneamento, municípios do interior e instituições educativas. Em todos os relatórios pesquisados, encontramos uma seção específica para tratar do Orfanato.

Tivemos acesso a esses materiais no arquivo Público do Pará e na Biblioteca Pública do "Centro Cultural Tancredo Neves" - CENTUR. Como instrumento facilitador dessa pesquisa, utilizamos máquina fotográfica digital, tendo em vista que tais materiais não poderiam ser emprestados, muito menos fotocopiados, e, sabendo do cuidado que devemos ter ao manuseá-los, optamos por fotografá-los para formarem o corpus desta pesquisa. Além desses documentos, para fundamentar as análises aqui apresentadas, lançamos mão dos estudos de Saviani (2007), Sarges (2002), Manoel (2006), Julia (2001), Rocque (1977), dentre outros estudiosos. 
Para o tratamento das fontes, utilizamos a análise documental-histórica, juntamente com o cruzamento dos dados, a fim de propiciarmos um melhor suporte e validação epistemológica. Dessa forma, analisar o pensamento de Lemos é perceber o dito e o não dito, o escrito e o silenciado fazendo a interseção entre as informações coletadas.

\title{
O CONTEXTO BELENENSE
}

No entendimento de Sarges (2010), a partir de1840, a atividade econômica na Amazônia passou a voltar sua atenção para a economia da borracha. Esse produto já vinha sendo utilizado na Europa, desde o início do século, como matéria prima para a produção de bens de consumo e impermeabilização de calçados. Tornou-se base da economia na Amazônia a partir do século XIX, depois da descoberta do método de vulcanização do látex por Charles Goodyear ${ }^{7}$.

De acordo com Sarges (2010), em Belém, estava o principal porto de escoamento do látex. Dessa forma, parte das riquezas produzidas pela extração do látex foi investida no setor público, mais especificamente na infraestrutura urbana e na reorganização do espaço urbano local. Nesse período, em Belém, ocorreram várias transformações, como: o calçamento de ruas; a construção de prédios como o do arquivo público e o "Teatro da Paz"; a criação de uma linha de bonde; a instalação de bancos e companhias seguradoras ligadas à nova economia da região. Essa reorganização do espaço urbano ocorreu em função do desenvolvimento da economia da borracha, culminado em uma materialização da modernidade que passou a se expressar por meio da construção de obras, da formação de novas classes sociais, e "na construção de um modelo ideal de sociedade moderna isento de perturbação" (SARGES, 2010, p. 87).

Foi-nos possível perceber também que ocorreram grandes transformações na estrutura social belenense, pois:

\begin{abstract}
A economia da borracha determinou alterações acentuadas na estrutura social belenense. Surge, então, uma classe de homens políticos e burocratas formada por nacionais; os comerciantes, basicamente portugueses; os profissionais liberais, geralmente de famílias ricas e oriundos das universidades européias. Esta era a composição da elite dominante (SARGES, 2010, p. 125).
\end{abstract}

Concomitante a essas mudanças, ocorreu, também, o surgimento de ofícios urbanos, realizados pela camada pobre da população, dentre esses, estão: o alfaiate; o sapateiro; o relojoeiro; os marceneiros.

Outro fator que contribuiu para as mudanças urbanísticas e sociais em Belém foi a migração de nordestinos, devido à seca no Nordeste na década de 1870 e à necessidade de mão de obra para trabalhar nos seringais. De acordo com Sarges (2010, p. 143), muitos dos nordestinos que desembarcavam não seguiam para os seringais e formavam "um elevado número de subempregados e também desempregados na capital do Pará".

As transformações em Belém ocorriam não para atender às necessidades básicas da maioria da população, mas estavam sujeitas às exigências do crescimento da economia e a nova elite belenense. Para Sarges (2010, p. 152),

a ação dinamizadora do "embelezamento do visual da cidade" estava associado à economia, à demografia, mas também aos valores estéticos 
de uma classe social em ascensão (seringalistas, comerciantes, fazendeiros) e às necessidades de se dar a determinados segmentos da população da cidade segurança e acomodação.

Esse desenvolvimento econômico era permeado de contradições sociais, pois, concomitantes às transformações urbanas e à implementação de novas tecnologias para a época, também havia a miséria, a prostituição, o inchaço urbano populacional e o aumento de epidemias. Conforme Sarges (2010, p. 157), "esses fatores demonstram o fausto e o luxo de uma burguesia que consumia, fundamentalmente, o importado".

Ao mencionarmos o consumo do importado referimo-nos ao movimento chamado de "Belle Époque", ocorrido em Paris (França). Tal movimento, com aspirações de modernidade, possuía tendências culturais que envolviam a arte, a moda, a postura, as construções. Essas características estavam arraigadas no imaginário das pessoas que passaram a ter a concepção de que tudo relacionado à França era sinônimo de modernidade, desenvolvimento, luxo e bom gosto. Essa concepção passou a fazer parte do imaginário paraense, levando a burguesia a reproduzir o modelo parisiense. Para Daou (2000), essas características ficaram evidentes também nas construções arquitetônicas e em outras partes urbanizadas de Belém, como logradouros, praças e parques ${ }^{8}$.

Com o intuito de fazer de Belém uma cidade que seguisse os moldes da Bella Época, foram realizadas várias ações em busca do "embelezamento da cidade". Surgiu, assim, uma política de disciplina e ordenação do espaço, onde não havia só o replanejamento urbano, mas também a criação de um "Código de Postura", para regulamentar a vida social. Esse contexto de regulamentações e reordenação da cidade foi marcado pela criação de vários espaços para abrigar pessoas desamparadas como mendigos e órfãos. Isso nos levou a conjecturar que o objetivo da criação dessas instituições era o de "limpar" as vias públicas, retirando de circulação as pessoas desvalidas que, de certa forma, "incomodavam" a elite que ali se firmava.

\section{ORFANATO COMO INSTITUIÇÃO EDUCATIVA}

Para Saviani (2007), as instituições são criadas para atender às necessidades humanas. Elas não podem ser concebidas como algo estático, visto que são históricas, possuindo, assim, um caráter transitório. As transições ocorrem de acordo com o tempo histórico decorrente das necessidades humanas. Com o "Orfanato Municipal Antônio Lemos" não foi diferente, pois essa instituição passou por várias transformações ao longo de sua história.

Ainda de acordo com Saviani (2007, p. 5),

para satisfazer necessidades humanas as instituições são criadas como unidades de ação. Constituem-se, pois como um sistema de práticas com seus agentes e com os meios e instrumentos por eles operados, tendo em vista as finalidades por eles perseguidas. As instituições são, portanto, necessariamente sociais, tanto na origem, já que determinadas pelas necessidades postas pelas relações entre os homens, como no próprio funcionamento, uma vez que se constitui como conjunto de agentes que travam relações entre si e com a sociedade a qual servem. 
Dentre as instituições criadas pelo homem, estão as instituições educativas, concebidas aqui de forma ampla, não especificamente com função educativa baseada em um plano pedagógico propriamente dito, mas que, de algum modo, tratam do processo ensino e aprendizagem e da transmissão de saberes.

Esse pensamento fundamenta-se em Castanho (2005, p. 40), ao afirmar que "instituição educativa é um termo mais amplo e abrange não somente a escola, como a conhecemos, no seu envolver histórico, mas também outras formas societais douradoras em que se desenrola o processo de transmissão cultural". É o caso do "Orfanato Antônio Lemos", que, além de abrigar meninas órfãs, também tinha como finalidade educá-las.

No entendimento de Rizzo (2003), os orfanatos e asilos foram criados para dar assistência às crianças órfãs de pai e mãe, crianças filhas de viúvas que precisavam trabalhar ou até mesmo de mães solteiras, que queriam esconder da população a gravidez indesejada, já que o fato de ser mãe solteira era vergonhoso perante a sociedade.

Marcílio (1998), ao produzir a História Social da Criança Abandonada, ressalta que a miséria se constituía um dos principais fatores para o abandono de crianças. Essa afirmação desconstrói a imagem generalizada que se criou em relação aos pais que abandonavam seus filhos, pois esses eram vistos como irresponsáveis e, muitas vezes, promíscuos e desumanos. Esta autora afirma que, durante a Idade Média, a preocupação com o destino das crianças "enjeitadas" passou a ser institucionalizada, de forma que os mosteiros passaram a aceitar essas crianças para que seguissem a carreira sacerdotal. No século XII, passou a existir um maior engajamento em relação à proteção dos meninos e meninas desvalidos. Já no século XVIII e XIX, surgiu a "Roda dos Expostos", , como forma de assistência a essas crianças.

Para Trindade (1999), o primeiro local para abrigar crianças foi construído em Milão, no ano de 787, por iniciativa do padre Datheus. Denominado de albergue, esse tipo de instituição, que não foi assumido diretamente nem pelo Estado, nem pela Igreja, foi difundido por toda a Europa.

Delobbe (2000), em sua obra Des enfants du XVI au XVIII siècle, ao retratar a infância em Paris, explica que, no ano de 1633, na França, foi criada uma instituição por Saint Vicent de Paul, "A Companhia das Filhas da Caridade", que tinha como missão educar e cuidar de todas as crianças encontradas nas ruas. Essa autora explica que, naquele ano, aumentou o número de crianças abandonadas nas ruas, hospitais e igrejas de Paris. Mesmo assim, só em 1793, o estado passou a dar mais atenção a esses menores, ao baixar um decreto, o qual afirmava que as crianças abandonadas seriam apoiadas pelo Estado e seriam chamadas d'enfants naturels de la Patrie (filhos naturais da Pátria). Nesse sentido, as comissões administrativas dos hospitais e a assistência pública passaram a dar maior atenção aos pequenos abandonados.

No início, essas instituições não tinham um plano com objetivos educacionais e profissionalizantes, visto que, para Hilsdorf (2005, p. 52), “o início da fase filantrópicocientífica da assistência dataria de meados do século XIX, quando a simples atividade de abrigo foi reorientada pela ideia utilitária de tirar as crianças da ociosidade". Nesse sentido, ao longo dos anos, os orfanatos foram ganhando novas configurações e passaram não só a abrigar crianças como também a educá-las para um ofício, ou, no caso das meninas, para serem boas mães e excelentes donas de casa.

No Brasil, a criação de abrigos para crianças estava ligada à filantropia e grande parte dessas instituições estava vinculada à Santa Casa de Misericórdia. Para Hilsdorf (2005, p. 53), a partir do século XVIII, fundamentada no pensamento iluminista, passou a ser concebida uma mentalidade de que a assistência aos necessitados não era apenas atribuição da Igreja, mas também uma responsabilidade pública. Essas ações deveriam ser 
mais ativas, de maneira que fossem "ao encontro dos pobres e infelizes para assisti-los e educá-los". Tais ações, de modo geral, passaram a ocorrer através de associações voluntárias, que criaram hospitais, asilos, maternidades e orfanatos. Os locais que abrigavam meninas pobres eram conhecidos por "Rodas de Expostos e Recolhimento".

$\mathrm{Na}$ concepção de Hilsdorf (2005), um dos primeiros locais em terras brasileiras destinados a abrigar e educar meninas foi o "Seminário de Educandas de São Paulo", autorizado para funcionar em 08 de janeiro de 1825 pelo imperador D. Pedro I. De cunho filantrópico, o objetivo dessa instituição era abrigar e formar meninas pobres desamparadas, órfãs de militares mortos em combates. Porém, muitas crianças também eram deixadas na "Roda de Expostos". No Pará, a implementação dessas instituições ocorreu alguns anos antes.

Conforme França e França (2011), em 1804, foi criado, na Província do Pará, o "Recolhimento das Educandas" pelo bispo Manoel de Almeida Carvalho, com o objetivo de amparar e educar meninas índias. Em 1851, essa instituição transformou-se no "Colégio Nossa Senhora do Amparo". Por meio de regulamento baixado pelo Presidente da Província do Pará, Fausto Augusto de Aguiar, naquele mesmo ano, o Colégio passou a proteger e educar meninas órfãs, pobres, desvalidas, expostas e pensionistas.

Com o intuito de amparar e educar meninas órfãs foi que a "Associação Protetora dos Órfãos", em 13 de maio de 1893, criou o "Orphelinato Paraense", o qual veio a se tornar Orfanato Antônio Lemos em 1906.

\section{O "ORFANATO ANTÔNIO LEMOS"}

O "Orfanato Antônio Lemos", cujas origens remontam ao Orphelinato Paraense, foi criado pela Associação Protectora dos Órphãos, em Belém, no ano de 1893, com objetivos comuns a grande parte desse tipo de instituição. Todavia, possui características únicas que fazem parte da construção de sua história, que, por sua vez, constitui sua própria identidade. Tais características perpassam pelas transformações que ocorreram nessa instituição, pelo conjunto de práticas educativas lá desenvolvidas, bem como pela cultura escolar nela presente.

Na perspectiva de Dominique Julia (2001, p. 356), cultura escolar pode ser entendida como "um conjunto de normas que definem conhecimentos a ensinar e condutas a inculcar, e um conjunto de práticas que permitem a transmissão desses conhecimentos e a incorporação desses comportamentos". Ainda na opinião desse autor, a cultura escolar leva a um remodelamento do comportamento dos que compartilham dessa cultura, que passa a disciplinar o corpo e a conduzir a própria consciência.

No período de instalação do Orphelinato, havia um número de nove órfãs. Porém, muitas meninas foram progressivamente sendo recebidas por essa instituição, que atingiu, em 1903, um número de oitenta e oito órfãs, sendo setenta e nove brasileiras e nove estrangeiras. Esse total foi divido em classes de $1^{\mathrm{a}}$ a $4^{\mathrm{a}}$ séries. Na primeira classe, estavam quatorze meninas; na segunda, trinta e duas; na terceira, dezoito; e, na quarta classe, vinte e quatro. Além disso, vinte e três das órfãs tinham idades entre 4 e 7 anos; vinte e quatro delas tinham entre 7 e 11 anos; e, quarenta e uma, com idades entre 11 e 18 anos. Esses dados do período demonstram que já havia um sistema seriado para a educação das órfãs. A idade das meninas variava de 4 a 18 anos, o que pode indicar a faixa etária em que as órfãs poderiam ser aceitas no Orfanato. 
Quanto à nacionalidade, eram setenta e sete órfãs brasileiras, sete da Espanha, duas do Peru e uma de Portugal. A naturalidade das brasileiras era, em sua maioria, paraense, mas havia órfãs do Ceará, do Maranhão e do Rio de Janeiro. Para saber de forma mais aprofundada sobre a origem dessas órfãs e o porquê de suas vindas para essa instituição e qual a ligação do Orfanato com esses países é necessário que seja realizado outro estudo focado nessas inquietações.

Ainda de acordo com o Relatório da Intendência Municipal de 1902, ao ser inaugurado em 1893, o Orfanato foi recebido com entusiasmo pela população paraense. A notícia era constantemente veiculada pelos principais jornais locais da época, o que contribuiu para que a nova instituição conseguisse vários sócios e muitos donativos. No período de sua inauguração, o número de sócios era de quinhentos e trinta e cinco, sendo quatrocentos e cinco homens e cento e trinta mulheres. Porém, três anos mais tarde, em fevereiro de 1896, o número de sócios efetivos foi reduzido para cento e dois. O "Orphelinato Paraense" teve seus sócios e as suas doações reduzidas a tal ponto que a receita arrecadada não era mais suficiente para cobrir as despesas da instituição, motivo que levou a "Associação Protetora dos Órfãos" a recorrer ao "Conselho Municipal de Belém”, com o intuito de conseguir ajuda financeira para a instituição.

A decisão do Conselho pode ser observada no trecho do Relatório (1902, p. 244), citado a seguir:

O Conselho, em sua última reunião do ano citado, resolveu tomar sob o patrocínio da Intendência o caritativo instituto, ameaçado de supressão pela carência de recursos. A resolução do legislativo municipal, n'este sentido, acha-se consignada na Lei $\mathrm{n}^{\circ}$ 283, de 27 de dezembro de 1900.

Ao analisarmos as fontes documentais, constatamos que, nos anos de 1900 e 1901, o Orphelinato recebeu ajuda financeira, porém, ainda não fazia parte da esfera municipal. Na descrição de Rocque (1977), o "Orphelinato Paraense" foi transferido em 17 de janeiro de 1901 para o âmbito da administração municipal, que passou a arcar com os recursos financeiros. No entanto, a instituição continuava sendo gerenciada internamente por religiosas da "Ordem Filhas de Sant'Ana".

No momento em que o Orfanato passou a ser responsabilidade da Intendência Municipal de Belém, iniciou-se uma atuação mais direta do Intendente Antônio Lemos. Rocque (1977) explica que, devido às condições do prédio serem precárias, Antônio Lemos arrendou outro, na Avenida São Jerônimo, hoje Avenida Governador José Malcher, entre a Avenida Generalíssimo Deodoro e a Travessa 14 de março, tentando oferecer melhores condições de vida às internas. Desse modo, depreendemos que o prédio que abrigava o Orfanato era alugado, ou seja, não tinha sede própria.

No ano de 1903, Antônio Lemos, por meio da Intendência de Belém, passou a ter maior autonomia sobre o Orfanato e ficou encarregado de reorganizá-lo e formatar a educação das órfãs ali abrigadas. Na direção interna dessa instituição, estavam mulheres religiosas, as "Filhas de Sant'Ana", sobre as quais tratamos a seguir. 


\section{A ORDEM RELIGIOSA FILHAS DE SANT'ANA}

Segundo a Revista Jubileu", que traz o título "Papiro da memória: 125 anos de presenças das Filhas de Sant'Ana no Brasil (1884 - 2009)", a "Ordem das Filhas de Sant'Ana" foi fundada na Itália pela Madre Ana Rosa Gattorno. Mas foi em outubro de 1884, que chegaram as seis primeiras irmãs "Filhas de Sant'Ana" no Pará, com o objetivo de cuidar dos enfermos do "Hospital do Bom Jesus dos Pobres", o qual, mais tarde, tornou-se a "Santa Casa de Misericórdia do Pará".

A vinda dessas primeiras religiosas foi liderada pela superiora Ir. Ana Victória Archetti e se concretizou depois que o bispo de Belém, Dom Antônio de Macedo Costa, e o Dr. Ferreira de Freitas, fundador do Hospital do Bom Jesus, fizeram o pedido à Madre Ana Rosa Gattorno, criadora da Congregação (REVISTA JUBILEU, 2009).

Ao desembarcarem no Brasil, encontraram um país que vivia o fortalecimento das ideias abolicionistas, a consolidação das ideias republicanas, a divisão e disputas entre Igreja e Estado, a expansão cafeeira, a chegada de imigrantes, a expansão das indústrias e o crescimento urbano. Na época, Belém despontava como principal rota de produção e comercialização do látex de borracha.

Podemos compreender também a vinda dessas religiosas como uma tentativa de expansão da Igreja Católica, visto que a primeira Constituição Republicana consolidou de fato a separação entre Igreja e Estado, devido às ideias laicas que tendiam a reger a estrutura jurídica e política no Brasil. Assim, a igreja percebeu as ações evangelizadoras como uma forma de continuar sua expansão.

Essa separação entre Estado e Igreja teve forte influência da Europa, mais precisamente da França. De acordo Manoel (1996), na França ocorreu o afastamento da Igreja em relação ao centro de decisões, principalmente em relação à educação, o que culminou com as reformas de Jules Ferry ${ }^{10}$, que foram decisivas para o laicismo educacional.

No Brasil, essa consolidação de laicismo educacional foi introduzida com a Constituição de 1891, sendo que a República não promoveu perseguição religiosa, nem confiscação dos bens da Igreja. Com isso, os bispos brasileiros publicaram uma carta pastoral aceitando a República, o que levou Rui Barbosa e D. Antônio Macedo Costa, bispo do Pará, a negociarem seus interesses (MANOEL, 2006 p. 18).

Em relação ao pensamento educacional, o Estado e a Igreja também divergiam. A educação naquele momento, na concepção do Estado, estava apoiada nas ideias do Projeto Liberal, que, para Manoel (1996, p. 18), previa formar "um homem apto a viver em sociedade sob a tutela da constituição, respeitando os direitos alheios, quaisquer que fossem, e tendo respeitado os seus próprios". Por outro lado, a Igreja tinha como objetivo a formação do cidadão para habitar o reino dos céus, ou seja, a cidade de Deus.

Mesmo com diferentes concepções educativas, podemos perceber que havia um jogo de interesses entre Estado e Igreja, fazendo com que ambos, mesmo discordando em seus ideais, mantivessem relações. A Igreja não aceitava o caráter individualista e laico do Liberalismo, e esse, queria afastar da Igreja o poder de tomar decisões.

No entanto, no Brasil do século XIX, na perspectiva de Manoel (1996), mesmo Estado e Igreja estando em conflito, muitas de suas ideias convergiam, uma vez que a concepção de sociedade, de poder político e de relações familiares apresentada pela

\footnotetext{
${ }^{1}$ No período estudado, não foi encontrado nenhuma relatório das Filhas de Sant'Ana , que administraram a instituição. Diante disso, nosso foco de análise voltou-se para os Relatórios da Intendência Municipal de Belém.
} 
Igreja Católica ajustava-se à vontade da oligarquia que dominava a sociedade daquele período.

Era perceptível que a Igreja vinha perdendo seu poder de tomar decisões e seu território em relação à expansão de suas ideias e a diminuição do número de seus seguidores. Podemos pensar, assim, que as congregações religiosas tinham o papel de ajudar a Igreja retomar as perdas que vinha sofrendo, porém, por meio de diferentes estratégias. Para a Revista Jubileu (2009), as congregações religiosas se engajavam pelo mundo com intuito de expandir a fé, fundamentadas no "Concílio Vaticano I". Nesse sentido, tentavam aliar o sagrado e o trabalho social ativo, atuando em hospitais, orfanatos, asilos de idosos e em escolas. Muitas mulheres religiosas, que faziam parte das congregações, assumiram importantes postos administrativos no Brasil. Esses grupos femininos ajudaram a expansão da Igreja Católica, ao mesmo tempo em que contribuíram para a formação da sociedade brasileira, o que pode ser observado na fala do teólogo Pe. Edênio Valle presente na Revista Jubileu (2009), quando afirma que:

As "irmãs de caridade" foram um dos fatores de maior peso na evolução da vida religiosa brasileira no final do Segundo Império. Elas passaram a ocupar postos dirigentes no campo da saúde, da educação e da assistência social, tornando a Igreja mais visível a sociedade e diante dos governos (VALLE apud REVISTA JUBILEU, 2009, p. 52).

Para esse teólogo, a contribuição que essas mulheres religiosas deram à sociedade é muitas vezes esquecida ou ignorada pelos estudiosos da história brasileira.

Depois que as primeiras "Filhas de Sant'Ana" se instalaram em Belém, outras desembarcaram em Manaus, no Maranhão, no Ceará e no Rio de Janeiro, enfim, passaram a atuar em todo o território brasileiro. Dentre as instituições que atuaram no Pará, estão o "Hospital do Bom Jesus", já citado; o "Hospital dos Alienados" (1887); o "Leprosário do Tucunduba" (1887); o início do "Primeiro Noviçado" (1889); o "Hospital São Luís" (1897); o "Orfanato Antônio Lemos" (1898), objeto deste estudo; o "Hospital Domingo Freire" (1900); o "Asilo da Mendicidade Dom Macedo Costa" (1902); o "Colégio Gentil Bittencourt" (1905); o "Colégio Santa Rosa" (1932); e o "Hospital São Sebastião" (1933).

De acordo com o Relatório Municipal (1902), no dia 19 de julho de 1898, foi assinado um contrato entre a "Associação Protetora dos Órfãos" e a "Ordem das Filhas de Sant'Ana", para que essas passassem a cuidar da administração do "Orphelinato Paraense". Assim, no dia $1^{\circ}$ de novembro do mesmo ano, o "Orphelinato Paraense" passou a ser administrado internamente por oito religiosas que faziam parte da referida Ordem.

A partir desses dados, podemos ter dimensão do trabalho desenvolvido pelas "Filhas de Sant'Ana" aqui no Pará, em relação à administração de várias instituições, dentre as quais se destaca o "Orphelinato Paraense". Nesse sentido, essas religiosas, de certa forma, contribuíram para a formação de muitas mulheres no Brasil. Essa visão também desconstrói o pensamento da época sobre o papel secundário da mulher na sociedade. Ao contrário, as mulheres sempre exerceram papéis fundamentais para a construção e desenvolvimento da sociedade, mas que foram, por muito tempo, silenciados pela história dita oficial.

Atualmente, ainda há religiosas dessa Ordem administrando várias instituições no Brasil. Algumas estão sob a sua administração desde que elas aqui chegaram, prova de que essas mulheres são exímias administradoras. No Pará, essas religiosas ainda estão na administração de instituições como o "Colégio Gentil Bittencourt"11, antigo "Colégio do Amparo", e o "Colégio Antônio Lemos"12, que teve suas origens no "Orphelinato 
Paraense", ou seja, a atuação dessas religiosas aqui no Pará está diretamente ligada à história do "Orfanato Antônio Lemos".

Apesar de ser administrado internamente pelas filhas de Sant'Anna, o Orphelinato passou para responsabilidade do município de Belém, de forma que o Intendente da época, Antônio Lemos, também conduziu tal instituição.

\title{
A EDUCAÇÃO DE MENINAS NA CONCEPÇÃO DE ANTÔNIO LEMOS
}

Antônio José de Lemos, durante sua gestão, atuou de forma significativa em relação ao Orfanato, de maneira que reformou o ensino das órfãs, ao mesmo tempo em que propôs transformar tal instituição em "Instituto Tecnológico". Para ter maior autonomia em relação à educação das órfãs e do Orfanato, Lemos publicou a Lei $n^{\circ} 370$, de 28 de Dezembro de 1903, por meio da qual o Orphelinato passou a denominar-se "Orphanato Municipal de Belém”. Essa lei também autorizava o Intendente a reorganizar o espaço do Orfanato e a dar novos moldes à educação das órfãs. Mas que educação era essa a qual Lemos se referia? Que mulher o Orfanato formaria na visão de Lemos? O trecho a seguir menciona características dessa educação preterida.

\begin{abstract}
Não se ensina n'essa casa os requintes que constituem a celebridade fugaz das grandes damas, cuja missão, desviada da naturalmente destinada à mulher, é conquistar, por meio de artifícios, triunfos banais e efêmeros, que a primeira ruga destrói implacavelmente. No Orphanato preparam-se mães de família laboriosas, modestas e dignas, incutindo-se no ânimo das educandas, os incomparáveis preceitos ensinados por Jesus Cristo, de par com o ensino das prendas domésticas (RELATÓRIO DA INTENDÊNCIA MUNICIPAL, 1903, p. 256).
\end{abstract}

Podemos perceber que, na opinião de Lemos, a mulher tinha que ser educada para o lar, aprender os afazeres domésticos, ser mãe de família boa e amorosa, que pudesse cuidar do marido. Não era uma educação qualquer, pois essa mulher teria que ter uma inteligência culta. Esse pensamento pode ser observado de forma mais explícita na citação a seguir, a qual demonstra a concepção do Intendente em relação à educação no Orfanato, o que para ele era a maneira "correta" de educar.

A mulher, no entanto, não pode ficar circunscrita ao gracioso ornamento do lar. É necessário que ela seja não só a mãe de família, tradicionalmente boa e amável, qual é a mulher brasileira, - mas também a companheira eficaz, de inteligência culta, que com o esposo compartilhe das lutas quotidianas, tornando menos fadigoso o trabalho d'aqueles (RELATÓRIO DA INTENDÊNCIA MUNICIPAL, 1903, p. 256).

No Orfanato, as educandas aprendiam as primeiras letras; instrução literária; as prendas domésticas até o bordado e branco; a educação física; e o ensino de música, o quanto fosse necessário para o Coral. Enfim, era prevista a formação de uma mulher culta, que soubesse ler, escrever, conversar, portar-se perante a sociedade e que fosse capaz de educar seus próprios filhos.

Gondra e Schuler (2008, p. 205) explicam que no século XIX havia um "discurso hegemônico", no qual às mulheres "era suficiente uma educação moral sólida, visando à 
formação de esposas e mães, em detrimento da instrução escolar propriamente dita". Oliveira $(2008$, p. 4) afirma que, no século XIX e início do século XX, "na escola se reforçava o papel da vida doméstica e limitava a educação da mulher ao papel de boa mãe e boa esposa, educadora de seus próprios filhos".

Na concepção de Manoel (1996), educar a mulher para dirigir a casa e comandar os escravos não era mais suficiente. Era preciso então ir além, educar e cultivar as jovens, para saberem ler, escrever, conversar. Tratava-se, assim, de uma educação voltada para o polimento sociocultural da mulher.

Com o intuito de dar uma melhor educação e amparar as meninas órfãs, no ano de 1903, o Intendente Antônio Lemos passou a articular um novo local, com área mais abrangente e com maior capacidade para instalar o Orphelinato. O local ideal por ele escolhido seria a Vila de Santa Izabel, distante 38 quilômetros da capital, Belém. O acesso a esse local se dava por veículo de tração animal, mas já estava sendo construída a Estrada de Ferro Belém-Bragança em cujo trajeto estava a Vila.

O Intendente sempre se importava em justificar a escolha da localização para a construção do novo prédio. Sua preocupação em dar uma melhor educação às órfãs era elemento recorrente em grande parte de seus relatos. No discurso de Lemos, podemos perceber o que Sarges (2002) chama de "remédio social", pois no seu entendimento era assim que o Intendente via a filantropia. Nesse sentido, era mais cômodo que as órfãs ficassem abrigadas longe do centro urbano. Era melhor deixar as mazelas sociais afastadas da área urbana da capital, em plena Belle Époque.

Nessa filantropia, podem estar implícitos os objetivos de controle, ordem e formação das meninas abrigadas no "Orfanato Antônio Lemos". Foucault (2010, p. 132) afirma que "o corpo está preso no interior de poderes muito apertados, que lhe impõe limitações, proibições ou obrigações". Nesse sentido, o Orfanato seria um mecanismo de controle do Estado em relação às meninas desvalidas, visto que esse, de maneira "dócil", lhes imporia disciplina.

Ao pensar em transferir o Orfanato, Lemos propôs-lhe uma nova configuração, a de transformá-lo em "Instituto Técnico e Profissional”, para trabalhos agrícolas.

[...] me parecia conveniente dar ao espírito e fins do antigo Orphelinato, propondo a sua transformação n'um Instituto Técnico profissional, para trabalhos agrícolas compatíveis com as aptidões e força das asiladas sem prejuízo do razoável cultivo de sua inteligência e do ensino dos misteres domésticos (RELATÓRIO DA INTENDÊNCIA MUNICIPAL, 1904, p. 255).

Para Lemos, além de serem boas mães e esposas amorosas e terem uma inteligência culta, as meninas órfãs também aprenderiam um ofício. A fundamentação desse pensamento de Lemos está presente no Relatório da Intendência Municipal de 1906, quando esse menciona o trabalho que vinha sendo desenvolvido pelo Diretor Geral de Agricultura na Bélgica, o Sr. Proost, em relação às escolas, principalmente, sobre o ensino agrícola feminino praticado naquele país. O mesmo Relatório descreve que o governo belga havia organizado um Curso de Economia Doméstica para mulheres em quinze lições, determinando que os locais agrícolas deveriam permitir mulheres em suas dependências. $\mathrm{O}$ documento refere-se também ao crescimento da indústria de lacticínios naquele país e do pleno êxito dessas escolas.

De acordo com o Relatório da Intendência Municipal de 1906, para Lemos, a iniciativa belga deveria servir de modelo para os demais países. Além disso, o Intendente afirmava estar de acordo com a importância da participação da mulher no trabalho do 
campo, o que para ele poderia se constituir como uma riqueza em prol do desenvolvimento do país. As questões aqui tratadas evidenciam que Lemos era um homem que acompanhava as ideias produzidas nos países mais desenvolvidos e procurava aplicá-las na educação das órfãs.

As obras do novo Orfanato na Vila de Santa Izabel foram iniciadas no ano de 1903. Em 1906, Lemos demonstrou sua ansiedade para transferir as órfãs e inaugurar o novo prédio, que, de acordo com ele, já tinha uma ala quase pronta. Naquele ano, a instituição passou a denominar-se "Orfanato Antônio Lemos", por meio da Lei Municipal no 433, de 15 de março de 1906. Essa mesma lei autorizou uma reforma no prédio, em Belém, onde as órfãs ainda estavam abrigadas.

De acordo com os indícios apontados nos Relatórios da Intendência Municipal, até o final do mandato de Antônio Lemos, no ano de 1912, as órfãs ainda não haviam sido transferidas para o novo prédio, que ainda estava por ser terminado. Esse fato pode ser explicado pela falta de recursos que estava se instalando em Belém, devido à queda na exportação da borracha. Concomitante à decadência econômica em Belém, que levou grandes empresas à falência, Lemos foi deposto do cargo por seus opositores políticos e expulso da capital. A casa do Intendente e o prédio de seu jornal "A Província do Pará" foram incendiados, o que resultou em um caos político local.

As educandas continuavam em Belém, morando no prédio alugado pela Intendência, até o ano de 1930, quando o Educandário, como também era conhecido o Orfanato, passou para o prédio da Vila de Santa Izabel. Naquele ano, ocorreu a "Revolução de 1930" e o Orfanato passou para o âmbito estadual, quando, então, teve sua construção finalizada. O novo contexto político, econômico e social que se instalava em Belém e a mudança do Orfanato para a Vila de Santa Izabel são inquietações para outros estudos.

\section{CONSIDERAÇÕES FINAIS}

No período de 1900 a 1906, a ideia de educação do Estado, fundamentada nas ideias liberais, previa formar o cidadão para viver de acordo com as leis criadas pelo homem em sociedade. Tal ideia divergia daquelas concebidas pela Igreja Católica que queria formar o ser para o reino de Deus (MANOEL, 1996). Além disso, muitas das ideias do projeto educativo pretendido, tanto pelo Estado, como pela Igreja Católica, convergiam, como as de formar boas mães de família. No discurso de Lemos, essa educação devia estar concatenada, visto que no Orfanato eram formadas laboriosas e dignas mães de família, que aprendiam as prendas do lar, ao mesmo tempo em que seguiam os preceitos dos ensinamentos do catolicismo.

Ao ter autonomia para reorganizar a educação das meninas no "Orfanato Antônio Lemos", o Intendente pensou uma educação que preparasse as órfãs para serem boas mães de família e que soubessem cuidar do marido e do lar, além de saberem as primeiras letras, música e literatura. Além disso, Lemos, ao resolver construir um novo prédio para o Orfanato em 1903, propôs transformá-lo em "Instituto Técnico e Profissional" para trabalhos agrícolas, onde as órfãs aprenderiam um ofício, sem prejudicar o cultivo da mente.

Dar um ofício para as meninas do Orfanato, para que pudessem aprender a mexer com a terra sem prejudicar o ensino das primeiras letras, ia além da concepção de educação pensado por Lemos anteriormente e, sobretudo, essa concepção de educação demonstra que Lemos estava concatenado com as ideias educacionais que ocorriam em outros países 
naquele período. Dar um ofício às órfãs, também desconstrói a ideia de que a educação para meninas naquela época era voltada somente para o cuidado com o lar e para que fossem boas mães de família.

Diferente das análises que buscam averiguar se a educação para a mulher é ou não para o lar, constatamos que as práticas do Orfanato estavam além desse tipo de educação, visto que as meninas tinham que aprender, também, a ler e a escrever, aprender música e ainda eram alvo de instrução literária. Ora, mas que ensinamentos musicais eram esses? Que tipo de música? Que literaturas eram essas? Os documentos a que tivemos acesso ainda não nos possibilitaram responder tais questionamentos que tanto nos instigam.

\section{REFERÊNCIAS}

ÁlBUM DO ESTADO DO PARÁ, 1908. Organizado por Ex. Sr. Dr. Augusto Montenegro Governador do Estado. Oito anos do Governo (1901 a 1903). PARIS, Imprimerie Chaponet (Jean Cussac), 7, Rue Bleue, 7.

BELÉM, Lei $\mathrm{n}^{\circ}$ 370, de 28 de Dezembro de 1903. Regula e reorganiza o Orphelinato Municipal. Intendência Municipal de Belém, 1903.

BELÉM, Lei Municipal $\mathrm{n}^{\circ}$ 433, de 15 de março de 1906. Autoriza a reforma do Orphelinato Municipal e o transforma em Orphanato Antônio Lemos. Intendência Municipal de Belém, 1906.

CASTANHO, Sérgio. Institucionalização escolar no Brasil: 1879 - 1930. Disponível em: <http://www.faced.ufu.br/colubhe06/anais/arquivos/525SergioCastanho.pdf >. Acesso em: 29/09/2011.

DAOU, Ana Maria. A Belle Époque Amazônica. (Descobrindo o Brasil). Rio de Janeiro: Jorge Zahar, 2000.

DELOBBE, Karine. Des enfants du XVI au XVIII siècle. Mouans-Sartoux, FR: PEMF, 2000.

FOUCAULT, Michel. Vigiar e punir: nascimento da prisão. Tradução de Raquel Ramalhete. 38. ed. Petropólis, RJ: Vozes, 2010.

FRANÇA, Maria do Perpétuo Socorro G. de S. A. de, FRANÇA, Samara A. de S. A educação de meninas órfãs e desvalidas no Colégio Nossa Senhora do Amparo (18601870). In: VI Congresso Nacional de História da Educação: Invenções, Tradições e Escrita da História da Educação no Brasil. Vitória, ES, 2011.

GONDRA, José Gonçalves \& SCHULER, Alessandra. Educação, poder e sociedade no Império brasileiro. São Paulo: Cortez, 2008.

HILSDORF, Maria Lúcia Spedo. Tão longe, tão perto - As meninas do seminário. In: STEPHANOU, Maria, BASTOS, Maria Helena Camara (Orgs). Histórias e memórias da educação no Brasil, vol. II: século XIX. Petrópolis, RJ: Vozes, 2005.

JULIA, Dominique. A Cultura Escolar como Objeto Histórico. Tradução de Gizele de Souza. Revista Brasileira de História da Educação. Campinas, SP: Autores Associados, 2001. 
LE COEUR, Marc. Os liceus na cidade: o exemplo parisiense (1802-1914). Educar em Revista [en línea] 2003. Disponível em Internet: http://www.redalyc.org/src/inicio/ ArtPdfRed.jsp?iCve=155017964018. ISSN 0104-060. Acesso em 30/11/2011.

MANOEL, Ivan A. Igreja e educação Feminina (1859 - 1919). Uma face do conservadorismo. São Paulo: Editora da Universidade Estadual Paulista, 1996.

MARCÍLIO, Maria Luiza. História social da criança abandonada. São Paulo: Hucitec, 1998.

OLIVEIRA, Lilian Sarat de. Educadoras e religiosas no Brasil do século XIX: nos caminhos da civilização. Disponível em: <http://www.uel.br/grupoestudo/processoscivilizadores/portugues/sitesanais/anais12/artigos/pdfs/comunicacoes/C_ Oliveira3.pdf>. Acesso em: 06/10/2011.

PARÁ. O município de Belém, 1897 a 1902: Relatório apresentado ao Conselho Municipal de Belém pelo Intendente Senador Antônio Lemos. Belém: Arquivo da Intendência Municipal, 1902;

O município de Belém. Relatório apresentado ao Conselho Municipal de Belém pelo Intendente Senador Antônio Lemos. Belém: Arquivo da Intendência Municipal, 1903.

O município de Belém. Relatório apresentado ao Conselho Municipal de Belém pelo Intendente Senador Antônio Lemos. Belém: Arquivo da Intendência Municipal, 1904.

O município de Belém. Relatório apresentado ao Conselho Municipal de Belém pelo Intendente Senador Antônio Lemos. Belém: Arquivo da Intendência Municipal, 1906.

REZENDE, Danielle Abrantes, LOPES, Léa. A extraordinária história da borracha: Charles Goodyear, inventor do processo de vulcanização da borracha. Disponível em http://146.164.6.5/uploads/2010/01/30/borracha_2.pdf. Acesso em: 19/10/2011.

RIZZO, Gilda. Creche: organização, currículo, montagem e funcionamento. 3. ed. Rio de Janeiro: Bertrand Brasil, 2003.

ROCQUE, Carlos. Historia de A Província do Pará. Belém: Mitograph, 1977.

SARGES, Maria de Nazaré. Belém: riquezas produzindo a Belle Époque (1870 - 1912). 3 ed. Belém: Paka-Tatu, 2010.

SARGES, Maria de Nazaré. Memórias do "velho intendente". Belém: Paka-Tatu, 2002.

SAVIANI, Dermeval. Instituições escolares no Brasil: conceito e reconstrução histórica. In: NASCIMENTO, Maria Isabel Moura et al (Orgs). Instituições Escolares no Brasil: conceito e reconstrução histórica. Campinas, SP: Autores associados, 2007.

TRINDADE, J.M.B. O abandono de crianças ou a negação do óbvio. In: Revista Brasileira de História. Dossiê infância e adolescência. São Paulo: ANPHU/HUMANITAS PUBLICAÇÔES, vol.19, n. 37, 1999.

VASCONCELOS, Ir. Rita M. de et al (Orgs). Papiro da Memória: 1884. 2009 - 125 anos de Presença das Filhas de Sant'ana no Brasil. In: Revista Jubileu. Edição Comemorativa. Fortaleza, CE: Sobral Gráfica, 2009. 


\section{Notas}

${ }^{1}$ Universidade do Estado do Pará Email: adrienepimenta@gmail.com

${ }^{2}$ Universidade do Estado do Pará Email: socorroavelino@ @otmail.com

${ }^{3}$ Partido político brasileiro criado em 1837, defendia os interesses dos senhores rurais e da classe média urbana, sem ligação direta com o movimento antiescravista, sendo extinto com a proclamação da República (MANOEL, 1996).

${ }^{4}$ Partido político brasileiro que tinha como objetivo manter o domínio político das elites escravocratas rurais (MANOEL, 1996).

${ }^{5} \mathrm{O}$ Conselho Municipal de cada município era composto de 6 a 12 vogaes. Os vogaes eram eleitos por 6 anos, renovando-se o Conselho no fim do terceiro ano pela metade. O território do Estado era dividido em 51 municípios, autônomos na gestão dos seus negócios, de forma que não podiam infligir as leis federais, bem como as do Estado. (O PARÁ, 1908).

${ }^{6}$ Politicamente o Estado do Pará era constituído por três poderes: o Legislativo, o Executivo e o Judiciário. O poder Legislativo era exercido pelo congresso com a sansão do governador e era composto pela Câmara dos Deputados e o Senado. A câmara era composta por 30 deputados eleitos por sufrágio direto e o Senado era composto por 18 senadores igualmente eleitos. (O PARÁ, 1908).

${ }^{7}$ Charles Goodyear foi um pesquisador americano, nascido no ano de 1800 , que descobriu o processo de vulcanização da borracha, o qual consistia na mistura do látex, leite retirado da árvore seringueira, com enxofre a uma temperatura de $130^{\circ}$ por um período aproximado de seis horas. Após esse processo a mistura ganhava consistência, tornando-se macia e seca, podendo ser utilizada na produção de calçados, roupas, pneus dentre muitos outros artefatos (REZENDE \& LOPES, 2008).

${ }^{8}$ Uma das literaturas que marcou a Belle Époque foi a de Charles Baudelaire, intitulada Flores do mal, publicada em 1857. Esta obra dimensiona e faz uma crítica às contradições entre a modernidade e as mazelas sociais que ocorriam na França em decorrências desse movimento.

${ }^{9}$ A "Roda dos Expostos" tem a forma de uma roda cilíndrica com uma divisória ao meio. Esse artefato era alocado na parede ou no muro das instituições que cuidavam de crianças abandonadas, de forma que ficasse móvel, girando. Assim, uma parte ficava acessível para a rua e a outra para dentro da instituição, sem que os dois lados pudessem ter contado visual. A criança enjeitada era deixada do lado externo do cilindro e próximo havia um sino, que deveria ser tocado para avisar a instituição que havia uma criança sendo abandonada (MARCÍLIO, 1998, p. 191).

${ }^{10}$ Foi primeiro ministro da França nos anos de 1880 a 1885, sua gestão foi decisiva para a consolidação do laicismo educacional. Adepto das ideias de Auguste Comte instituiu as leis que tornaram oficialmente o ensino primário gratuito e obrigatório na França (LE COUER, 2003).

${ }^{11}$ Localiza-se na Avenida Nazaré, entre a Travessa 14 de março e a Avenida Alcindo Cacela.

${ }^{12}$ Localiza-se na Avenida Senador Lemos, em Santa Izabel do Pará, distante 38 km de Belém.

Recebido: Agosto-2012

Aprovado: Abril-2013 